\title{
Reflexões iniciais sobre a prática colaborativa e a educação especial
}

\author{
Alejandra Cesarina Rodriguez Paz \\ Sonia Lopes Victor \\ Universidade Federal do Espírito Santo (Brasil)
}

\section{Resumo}

A colaboração entre o professor de sala de aula regular e o da educação especial revela-se como uma das práticas essenciais para garantir o direito à educação ao grupo de alunos público-alvo da educação no movimento de inclusão escolar. Nessa direção, esse trabalho visa a fortalecer a discussão no Brasil a respeito da colaboração docente pela via de sua problematização. Realiza um ensaio crítico a fim de evidenciar o termo em estudos internacionais que indicam sua origem e sua vinculação epistemológica. Por conseguinte, o texło aborda as seguintes temáticas: terminologia e conceituação; ensino em equipe; colaboração na educação especial; consulta escolar colaborativa; e coensino e ensino colaborativo. Ao final, observa que os diversos modelos de colaboração parecem estar alinhados ao conceito utilizado pelas organizações/empresas, com o intuito de resolver problemas correspondentes ao modo de produção capitalista e atingir a eficácia do processo de ensino.

Palavras-chave: Colaboração. Educação especial. Prática colaborativa. Inclusão escolar.

\section{Initial reflections about the collaborative practice and special education}

\begin{abstract}
The collaboration between the regular classroom teacher and the special education teacher is revealed as one of the essential practices to guarantee the right to education for the group of special students in the school inclusion movement. In this sense, this work aims to strengthen the discussion in Brazil regarding teaching collaboration through its problematization. It conducts a critical essay in order to highlight the term in international studies that indicate their origin and its epistemological link. Thus, the text addresses the following topics: terminology and conceptualization; team teaching; collaboration in special education; collaborative school consultation; and co-teaching and collaborative teaching. At the end, it observes that the various models of collaboration seem to align with the concept used by organizations/companies, in order to solve problems corresponding to the capitalist mode of production and achieve the effectiveness of the teaching process.

Keywords: Collaboration. Special education. Collaborative practice. School inclusion.
\end{abstract}




\section{Reflexiones iniciales sobre la práctica colaborativa e la educación especial}

\section{Resumen}

La colaboración entre el maestro de aula regular y el maestro de educación especial se revela como una de las prácticas esenciales para garantizar el derecho a la educación del grupo de estudiantes especiales en el movimiento de inclusión escolar. En esa dirección, este trabajo busca fortalecer la discusión en Brasil sobre la colaboración docente a través de su problematización. Realiza un ensayo crítico con el objetivo de evidenciar el término en estudios internacionales que indican su origen y su vinculación epistemológica. Por tanto, el texto aborda los siguientes temas: terminología y conceptuación; enseñanza en equipo; colaboración en la educación especial; consulta escolar colaborativa; y co-enseñanza y enseñanza colaborativa. Al final, observa que los diversos modelos de colaboración parecen estar alineados al concepto utilizado por las organizaciones/empresas, con el propósito de resolver problemas correspondientes al modo de producción capitalista y alcanzar la eficacia del proceso de enseñanza.

Palabras clave: Colaboración. Educación especial. Práctica colaborativa. Inclusión escolar.

\section{Introdução}

A inclusão escolar do aluno público-alvo da educação especial implica a garantia do direito à educação por meio da construção de alternativas que viabilizem todas as escolas se constituírem como espaços adequados para o desenvolvimento desse educando, possibilitando sua autonomia social e intelectual, assim como as condições para o exercício de sua cidadania (PRIETO, 2008).

Além do acesso, é necessário garantir a permanência e a apropriação de conhecimento do aluno na escola diante de suas necessidades educacionais particulares, por meio de recursos e práticas de ensino-aprendizagem que tenham em vista um processo de inclusão não excludente (CURY, 2016).

Nesse contexto, a colaboração entre o professor de sala de aula regular e o da educação especial se revela como uma das práticas que fazem parte do discurso em prol desse movimento.

No Brasil, a colaboração entre os professores de sala de aula regular e os da educação especial é mencionada pela primeira vez na Resolução CNE/CEB n² 2, de 11 de setembro de 2001 (BRASIL, 200 1), que estabelece as Diretrizes Nacionais para a Educação Especial na Educação Básica. 
Em 2008, foi publicada a Política Nacional de Educação Especial na Perspectiva da Educação Inclusiva (PNEEPEI) (BRASIL, 2008), que define a educação especial como uma modalidade transversal de ensino que perpassa todos os níveis, etapas e modalidades da educação. Esta não substitui o ensino regular, que oferta o atendimento educacional especializado de forma complementar e/ou suplementar a todos os alunos público-alvo da educação especial matriculados em classes comuns com o objetivo de assegurar a esses estudantes sua inclusão no ensino regular.

Por conseguinte, conforme Prieto, Cosmo e Anache (201 8), a educação especial passa a integrar a proposta pedagógica da escola, assumindo um caráter pedagógico e distanciando-se, cada vez mais, da perspectiva assistencialista/clínica de atendimento com o objetivo de dar ênfase ao desenvolvimento de sistemas educacionais inclusivos. Nesse sentido, a educação especial passa a ser organizada como apoio à aprendizagem no ensino regular de alunos público-alvo da educação especial na sala de aula tradicional.

Dessa maneira, a colaboração entre os professores de sala regular e os da educação especial é mencionada na PNEEPEl, vagamente, como "desenvolvimento de práticas colaborativas", referindo-se a uma das ações da educação especial no âmbito de uma atuação mais ampla na escola (BRASIL, 2008). Contudo, o documento não especifica como devem ser organizadas essas práticas, nem quem são os sujeitos responsáveis pela sua materialização.

Em contrapartida, a Resolução CNE/CEB n $n^{\circ}$, de 2 de outubro de 2009 (BRASIL, 2009), que institui as Diretrizes Operacionais para o Atendimento Educacional Especializado na Educação Básica, ressalta, indiretamente, em seu art. 9, a articulação entre os professores de sala regular, os da educação especial e também outros profissionais ao referir-se à elaboração e execução do plano de Atendimento Educacional Especializado (AEE). Já no art. 13 do referido documento, a colaboração entre esses profissionais é definida como uma das atribuições do professor do AEE, com o objetivo de disponibilizar os serviços, os recursos pedagógicos e as estratégias que incentivam a participação dos alunos nas atividades escolares.

Com base nos documentos legais e orientadores apresentados, observamos que a prática colaborativa entre os professores regentes e os da educação especial apenas é citada e, às vezes, definida superficialmente. Consequentemente, fica a cargo dos pesquisadores explicitar as características dessa parceria em seus estudos e também do Poder Público em materializar 
a colaboração como uma das possibilidades educacionais de atuar frente à garantia da aprendizagem dos alunos público-alvo da educação especial na escola regular, por meio de políticas públicas para essa modalidade nos âmbitos estadual e municipal.

Os termos "ensino colaborativo" ou "coensino", presentes nas primeiras pesquisas brasileiras, reproduzidos do inglês - co-teaching e collaborative teaching -, provenientes de literatura estrangeira, são definidos como um dos modelos de prestação de apoio no qual o professor de ensino regular e o da educação especial dividem a responsabilidade de planejar, instruir e avaliar o ensino oferecido a um grupo heterogêneo de estudantes (CAPELLINI, 2004; ZANATA, 2004).

Compreendemos, assim, que o conceito de colaboração se insere em uma totalidade histórica composta por uma dinâmica de contradições, mediações e determinações políticas, econômicas e sociais da educação especial no Brasil, que se expressa por uma multiplicidade de termos coincidentes nos estudos brasileiros.

Com o intuito de fortalecer essa discussão no Brasil, pela via de sua problematização, buscamos, neste ensaio crítico, evidenciar o termo em estu-

4 dos internacionais que indicam sua origem e sua vinculação epistemológica. O objetivo é adensar, em trabalhos futuros, "[... ] a crítica e o conhecimento crítico para uma prática que altere e transforme a realidade anterior no plano do conhecimento e no plano histórico-social" (FRIGOTTO, 1991, p. 89) a respeito desse tema no campo da educação especial brasileira.

\section{Colaboração: conceituação}

A partir do estudo de Garcia (2016), inferimos que o conceito de colaboração tem sua origem na década de 1950, no auge da teoria do desenvolvimento organizacional aplicada nas fábricas dos Estados Unidos.

A colaboração configura-se como uma ferramenta para alcançar as mudanças na organização e atingir os objetivos desejados, partindo da definição do desenvolvimento organizacional como a aplicação do conhecimento da ciência comportamental para o planejamento, o desenvolvimento, a promoção e a ênfase em estratégias, estruturas e processos organizacionais, visando a melhorar a eficácia na organização (GHORBANHOSSEINI, 2013). Sendo 
assim, é conceituada como um dos fundamentos da teoria organizacional sob a forma de trabalho em equipe:

[...] o trabalho em equipe é uma preocupação mental e emocional dos indivíduos em situações de grupo que os motiva a ajudar uns aos outros para alcançar os objetivos grupais e participar da responsabilidade do trabalho. $\bigcirc$ trabalho em equipe é uma ferramenta para aumentar a criatividade, o que implicitamente leva à consolidação da satisfação no trabalho (GHORBANHOSSEINI, 2013, p. 1020, tradução nossa).

Conforme as ideias de Emery e Trist, destacadas por Appley e Winder (1977), a importância da colaboração na mudança organizacional é explicada pela necessidade de se enfrentar os crescentes níveis de complexidade, interdependência e incertezas que caracterizavam os ambientes turbulentos constituídos na sociedade pós-industrial.

De acordo com Damanpour e Gopalakrishnan (1998), o ambiente de uma organização é definido como um sistema que está fora da organização que influencia o comportamento e as propriedades da organização. Nessa perspectiva, os ambientes turbulentos constituem-se por propriedades dinâmicas que surgem tanto da interação das unidades individuais dentro da organização como daquelas decorrentes de seu próprio campo social (EMERY; TRIST apud APPLEY; WINDER, 1977).

Desse modo, as exigências geradas nesses ambientes não podiam ser enfrentadas pelos sujeitos ou pela organização individualmente, portanto, buscou-se quebrar o sistema hierárquico baseado nos valores competitivos e no conflito de auto interesse por meio do estabelecimento de novos valores de comportamento que caminhassem para a configuração de outro sistema, fundamentado no compartilhamento e na confiança entre seus membros (TRIST, 1977; APLEY; WINDER, 1977).

Nesse contexto, Appley e Winder (1977) apontaram a colaboração como base de um novo sistema de valores, no qual o cuidado e a preocupação sejam comportamentos manifestados pelos membros do sistema em relação ao outro, configurando um sistema relacional. Dessa maneira, a colaboração é definida como: 
[...] um sistema relacional em que: a) os indivíduos num grupo compartilham aspirações mútuas e um quadro conceptual comum; b) as interações entre os indivíduos estão caracterizadas pela "justiça como equidade"; e c) essas aspirações e conceituações estão caracterizadas pela consciência individual de seus motivos para $\circ$ outro, pelo cuidado ou pela preocupação com o outro e pelo compromisso de trabalhar com o outro ao longo do tempo, desde que esse compromisso seja uma questão de escolha (APPLEY; WINDER, 1977, p. 281 , tradução nossa).

De acordo com a citação anterior, na interação colaborativa, o cuidado e a preocupação entre os indivíduos são possíveis por meio da manutenção do equilíbrio do sistema relacional. Desse modo, o equilíbrio apoia-se na reciprocidade entre membros, a qual exige a equidade do mérito e a permuta de benefícios (BOSZORMENYI-NAGY; SPARK, 1973).

Conforme Appley e Winder (1977), o mérito tem uma natureza subjetivamente ponderada e estabelece-se como um excedente moral armazenado, considerado um ganho por atos de desempenho justos, como garantia de benefícios futuros. Já a permuta de benefícios é concebida como a doação e aceitação de cuidados relacionadas com a exploração de um indivíduo pelo outro. Nessa perspectiva, a exploração constitui a satisfação das necessidades individuais que não envolvem reciprocidade, manifestando-se como um sentimento subjetivo de que uma pessoa é usada por outra.

Os autores afirmam que a atuação desses conceitos é explicitada no sistema relacional hierárquico, em que o trabalhador (ou o explorado), ao ser considerado um instrumento para a manutenção da produtividade do produto, tem direito ao mérito e menos responsabilidade de ser o cuidador; e o empregador (ou explorador) tem pouco direito de ser cuidado e maior responsabilidade para cuidar do outro. Em contrapartida, no novo sistema de relações colaborativas, a conjuntura será a mesma. Porém, com o trabalhador consciente de sua situação e o empregador sensível a ela, a exploração de cada membro será equilibrada pelo cuidado, isto é, pela disponibilidade com o outro, como uma pessoa que se preocupa, que cuida; pela disposição de reparar com o outro as injustiças passadas; e pelo reconhecimento do serviço meritório realizado por outro membro.

Nessa lógica, Boszormenyi-Nagy e Spark (1973) explicam que, nos sistemas relacionais, a reciprocidade do cuidado e da preocupação experimentada pelos participantes transcende seus processos psicológicos ao entrar 
no campo da ação ou do compromisso com a ação. Desse modo, a ação ou o comportamento movimentam as pessoas além de sua separada existência, levando-as para o grupo.

Por conseguinte, a consciência do novo sistema de valores e o reconhecimento da necessidade tanto de cuidar como de ser cuidado pelos outros são promovidos pelo comprometimento com o sistema de valores e com as pessoas. Portanto, o equilíbrio do sistema dependerá do esforço colaborativo dos membros para torná-lo um sistema justo, baseado no comprometimento do cuidado e na preocupação mútua entre os indivíduos que compartilham a participação no grupo de trabalho, com o objetivo de corrigir os erros sofridos pela exploração de um ou mais membros (APPLEY; WINDER, 1977).

De forma geral, a colaboração configura-se dentro da lógica de um novo sistema relacional, no qual se busca reparar os erros que causam sofrimento ao trabalhador no sistema relacional hierárquico. Nesse sentido, a exploração que existia no antigo sistema, pautada no mérito e na troca de benefícios, passa a ser reconfigurada e equilibrada por meio da colaboração baseada no cuidado, na preocupação, no compartilhamento, no compromisso, na reciprocidade e no reconhecimento mútuo entre os funcionários e os líderes da organização/empresa.

Assim sendo, a colaboração permite que o trabalhador perceba sensações de cuidado e preocupação do outro a seu respeito, indo além dos seus processos psicológicos e fazendo-o comprometer-se com seu trabalho, pois ele sente que não está mais sozinho; agora faz parte de um grupo com o qual será capaz de atingir da melhor maneira as metas produtivas esperadas, melhorando a eficácia da organização/empresa.

Nessa perspectiva, observamos que a colaboração se conceitua dentro de um sistema relacional de trabalho em conjunto como uma ferramenta psicológica aplicada aos trabalhadores para gerar mudanças organizacionais e atingir objetivos relacionados com a produção eficaz da organização/ empresa. Consequentemente, sob a base de um sistema relacional de trabalho em conjunto, caracterizado pelos discursos de cuidado humano, compromisso e justiça, a colaboração é estabelecida como parte da reconfiguração do sistema capitalista, que continua explorando o trabalhador por meio de novos mecanismos que melhorem sua produtividade e proporcionem maiores lucros econômicos. 
Com base nesses fundamentos, a escola, que faz parte de uma totalidade econômica, também é alvo de mudanças organizacionais. No próximo tópico mostraremos como a colaboração é aplicada na escola com o objetivo de investir num padrão organizacional escolar que vise a melhorar a qualidade e eficácia do ensino (LITTLE, 1981).

\section{A colaboração e o ensino em equipe}

A expressão "ensino em equipe" surgiu pela primeira vez em 1957, na revista científica Education Digest, em decorrência de um estudo realizado sobre a utilização da equipe escolar pela Associação Nacional de Diretores das Escolas Secundárias (Nassp, sigla em inglês), financiado pelo Fundo para - Avanço da Educação dos Estados Unidos. O objetivo do estudo foi elaborar novas abordagens para alguns dos problemas enfrentados pelas escolas norte-americanas (MYERS, 1968).

Dentre os problemas educacionais da época, Myers (1968) destaca, em primeiro lugar, que o número de matrículas das escolas públicas no ensino fundamental e médio aumentou significativamente, devido ao rápido crescimento da população nos Estados Unidos após a Segunda Guerra Mundial, levando à escassez de professores. Esse fato também se explica pelo surgimento de novas profissões ou pela mudança do perfil profissional, que era reservado exclusivamente para homens, dando a oportunidade para as mulheres se inserirem em outras áreas diferentes do ensino.

Em segundo lugar, a autora aponta que a expansão do conteúdo curricular nas escolas de ensino fundamental exigiu que o professor lidasse com novos conceitos, conhecimentos e habilidades, assim como acompanhasse todas as inovações de sua profissão. Desse modo, buscou-se uma maneira de aliviar a carga do professor, sem deixar de oferecer uma educação menos completa.

Por último, os novos descobrimentos da época sobre o crescimento e desenvolvimento das crianças demonstraram que as habilidades intelectuais medidas pelo coeficiente intelectual não eram suficientes para antecipar o sucesso acadêmico. Portanto, as particularidades da criança passaram a ser consideradas. A elas era oferecida uma abordagem individualizada.

Diante desse contexto, Myers (1968) afirma que a pesquisa da Nassp se voltou para as mudanças organizacionais escolares por meio da aplicação 
de vários programas empíricos nas escolas norte-americanas de todos os níveis, os quais abrangiam o desenvolvimento de currículos, métodos de ensino e formas de utilizar o espaço e a equipe.

Como resultado da variedade de projetos empreendidos, em 1957, a escola de ensino fundamental Franklin, em cooperação com a Universidade Howard, desenvolveu o primeiro programa de ensino em equipe, que repercutiu em todas as escolas estadunidenses. $\bigcirc$ ensino em equipe é conceituado como:

[...] um arranjo por meio do qual dois ou mais professores, com ou sem professores auxiliares, planejam cooperativamente, ensinam e avaliam um ou mais grupos de alunos em um espaço de ensino apropriado e um determinado período de tempo, assim como uma apropriação da vantagem das competências singulares dos membros da equipe (TRUMP; BAYNHAM, 1961, p. 16, tradução nossa).

Shaplin e Olds (1964) oferecem uma definição similar ao estabelecer a diferença entre o ensino em equipe e os acordos colaborativos informais por meio de três características necessárias para uma situação de ensino legítima em equipe. Primeiro, o ensino em equipe tenta assegurar a efetividade e continuidade desses acordos de trabalho, restringindo o desejo dos membros da equipe de voltar a ter uma sala de aula e um planejamento independente. Segundo, as equipes de ensino são compostas por dois ou mais membros profissionais devido ao ensino de responsabilidades compartilhadas, assumidas em sua relação de trabalho. Por último, é a variedade no planejamento, no agrupamento e na localização no espaço dos alunos que designa um grupo de estudantes a uma equipe de ensino. A ausência de uma ou mais dessas características implica a falta de um verdadeiro programa de ensino em equipe.

Conforme Myers (1968), o ensino em equipe é, em grande medida, um conceito organizacional, já que é uma forma de organizar a escola numa base horizontal enquanto os outros tipos de organização são essencialmente verticais, movimentando os estudantes de forma crescente na escola.

Esse tipo de organização implica que as relações de trabalho se caracterizem pela interação efetiva entre os membros da equipe, visando ao compromisso formal e à aceitação de responsabilidade por parte de cada um deles (MYERS, 1968; LITTLE, 1981 ). 
Nessa perspectiva, Little (1981) considera que a interação efetiva do ensino em equipe dependerá do comportamento dos professores e de suas percepções em relação às suas expectativas compartilhadas e não às suas preferências individuais; em vez disso, eles se fundamentam no conhecimento socializado do comportamento (a conversa e a ação) e são considerados parte apropriada de ser professor. $\bigcirc$ conhecimento compartilhado é acumulado no curso da interação diária no trabalho. É exibido em pequenas e grandes formas, dia após dia, na forma como os professores lidam com seu trabalho. É a base sobre a qual as pessoas se envolvem com os outros e interpretam o que veem e ouvem.

Em linhas gerais, o autor ressalta que, com base em uma abordagem colaborativa, o "ensino em equipe" proporciona aos professores ocasiões estruturadas e contínuas para se ganhar clareza sobre objetivos, perspectivas, métodos e papéis da educação e sobre suas expectativas recíprocas do ensino. Dessa forma, as expectativas sobre a eficácia da organização escolar tornam-se mensuráveis.

Nessa direção, não podemos perder de vista que o modelo de ensino em equipe visa à reorganização do sistema de relações, passando de uma 10 estrutura organizacional hierárquica para uma estrutura horizontal, baseada nos pressupostos do compromisso e da responsabilidade pelos membros da instituição, com o objetivo de atingir a eficácia escolar. Desse modo, percebemos uma perspectiva muito similar à ferramenta de colaboração utilizada nas organizações/empresas.

Isso posto, nossa preocupação a seguir é com a conceituação da colaboração entre o professor de sala de aula regular e o da educação especial.

\section{A colaboração na educação especial}

Entre as décadas de 1980 e 1990, a diminuição da capacidade de competir no mercado internacional levou ao declínio de status dos Estados Unidos como líder global. Nesse contexto, sob a justificativa de que o restabelecimento da liderança econômica do país dependeria de uma juventude norte-americana mais instruída, foi desenvolvido um conjunto de reformas educacionais. Por conseguinte, as escolas passaram por mudanças significativas que envolveram a capacidade da equipe escolar para colaborar com o 
objetivo de preparar efetivamente os estudantes para se tornarem trabalhadores produtivos e líderes nacionais necessários (FRIEND; COOK, 1990).

Dessa maneira, a educação especial, como parte da totalidade da educação, também evidenciou a relação econômica entre o desenvolvimento de relações colaborativas e práticas de ensino e o objetivo de tornar os alunos com deficiência, problemas de aprendizagem e/ou comportamentais pessoas produtivas para o mercado de trabalho.

Essa proposição é afirmada por West e ldol (1990), quando ressaltam que, com o objetivo de reduzir as despesas da educação especial, foi estabelecida a colaboração entre os profissionais como alternativa de resolução de problemas dos alunos indicados para a educação especial:

[...] a necessidade de colaboração é evidente a partir de um abrangente estudo sobre os custos da Educação Especial, publicado pela Decision Resource Corporation, para o Departamento de Educação dos EUA para o ano letivo de 1985-1986 (EUA, Departamento de Educação, 1985-1986). O relatório evidencia, - que não é surpresa para os envolvidos na educação especial, que aproximadamente $5 \%$ de todos os alunos estadunidenses são avaliados anualmente pela educação especial, e esses serviços de avaliação representam 12 centavos de cada dólar gasto para a educação especial ou cerca de US \$ 2 bilhões por ano [...]. Como uma alternativa ao paradigma de encaminhamento-diagnóstico-colocação, a colaboração entre os profissionais da escola está sendo iniciada em muitos distritos escolares visando a prevenir os problemas de aprendizagem e comportamento dos alunos. O objetivo desses serviços escolares de apoio é atender às necessidades individuais dos alunos antes da necessidade do encaminhamento para a possível colocação em um programa especializado (WEST; IDOL, 1990, p. 1, tradução nossa).

Da mesma forma, os autores asseveram que os resultados da pesquisa realizada pelo Conselho para Crianças Excepcionais dos Estados Unidos apontaram a necessidade de colaboração entre os professores de ensino regular e os da educação especial. Foi estabelecida uma das áreas fundamentais para o desenvolvimento profissional dos membros da escola, assim como para o estabelecimento de escolas eficazes.

Nesse sentido, a colaboração passa a ser usada como uma alternativa para facilitar a relação entre o professor de sala de aula e o da educação especial, com o objetivo de tornar essa relação mais eficaz e melhorar a qualidade 
de ensino dos alunos com problemas de aprendizagem, baixo desempenho ou excepcionais nas salas de aula regulares (WEST; IDOL, 1987).

Portanto, a seguir, discutiremos os modelos de consulta escolar colaborativa e o coensino, ou ensino colaborativo, como duas formas de organização por meio das quais a colaboração foi materializada nos Estados Unidos durante as décadas de 1980 e 1990, amplamente difundida no Brasil a partir de 2000.

\section{A consulta escolar colaborativa}

Em linhas gerais, o conceito de "consulta", conforme Meyers, Parsons e Martin (1979), baseia-se nas proposições da escola de psicologia, da saúde mental e do desenvolvimento organizacional. Consulta é definida como:

Uma técnica que, no mínimo, sempre tem as seguintes seis características: a) é um processo de ajuda para a solução de problemas; b) ocorre entre um profissional que oferece ajuda e um solicitante dela, os quais têm a responsabilidade pelo bem-estar de outra pessoa; c) é um relacionamento voluntário; d) conta com um profissional que oferece ajuda a um solicitante e ambos compartilham a resolução do problema; e) tem como objetivo ajudar a resolver um problema atual de trabalho do profissional que busca ajuda; e f) é o lucro dos profissionais que buscam ajuda por meio do relacionamento, fazendo que os problemas futuros talvez sejam tratados com mais sensibilidade e habilidade (MEYERS; PARSONS; MARTIN, 1979, p. 4, tradução nossa).

Nessa perspectiva, West e Idol (1987), citando Tharp (1975), referem-se à consulta como um processo em tríade caracterizado por uma relação interativa entre consultor, consultado e cliente. Dessa maneira, o consultor auxilia outro profissional, o consultado, na resolução de um problema de trabalho frequente relacionado com um cliente pelo qual o consultado é responsável na orientação para lidar com problemas semelhantes no futuro (MEYERS; PARSONS; MARTIN, 1979; WEST; IDOL, 1987).

No contexto escolar, a tríade consultiva desenvolve-se a partir da prestação de serviços indiretos e suporte de qualquer professor especialista em aprendizagem ou comportamento (o consultor) para o professor de sala de aula regular (o consultado) sobre um assunto associado a um aluno específico 
(o cliente), o qual é a principal responsabilidade do professor de sala de aula regular (HERON; HARRIS, 1982; IDOL; PAOLUCCI-WHITCOMB; NEVIN, 1986; IDOL-MAESTAS, 19811.

Conforme West e ldol (1990), o conceito tradicional de consulta consistia na relação de um profissional atuando com outro em busca de orientação para resolver um problema existente, sem uma relação de colaboração baseada no trabalho em conjunto de dois ou mais profissionais, caracterizada pela paridade e reciprocidade, visando à resolução de problemas.

Portanto, Brown, Wyne, Blackburn e Powell propuseram a natureza colaborativa da consulta, explicitada na seguinte definição:

A consulta é geralmente um processo baseado em um relacionamento igual caracterizado por confiança mútua e comunicação aberta, abordagens conjuntas para a identificação de problemas, agrupação de recursos pessoais para identificar e selecionar estratégias que terão alguma probabilidade de resolver o problema que foi identificado e compartilhar a responsabilidade na implementação e avaliação do programa ou estratégia que foram iniciados (BROWN; WYNE; BLACKBURN; POWELL, 1979, p. 8, tradução nossa).

Com base nessa definição, o papel do consultor transforma-se de um especialista que, simplesmente, aconselha e guia os outros, para o de um colaborador facilitador e competente capaz de encaminhar os outros para a solução de problemas compartilhados e mútuos por meio da implementação de planos e programas de avaliação (WEST; IDOL, 1990).

Nessa perspectiva, a consulta colaborativa passa a ser conceituada como uma opção de prestação de serviços da educação especial que deve acontecer entre os professores de educação especial e os da sala de aula regular. $\bigcirc$ objetivo é construir meios de apoio para a integração na educação regular dos estudantes de educação especial com problemas de leve aprendizado e/ou comportamentais, assim como de alguns educandos com deficiência moderada ou com baixos níveis de alcance (IDOL; PAOLUCClWHITCOMB; NEVIN, 1986; WEST; IDOL, 1987). Dessa forma, a consulta colaborativa é caracterizada como:

[...] um processo interativo que permite às equipes de pessoas com diversos conhecimentos gerar soluções criativas para problemas mutuamente definidos. O resultado é aprimorado, alterado e 
produz soluções que são diferentes daquelas que o membro da equipe individual produziria independentemente. $\bigcirc$ principal resultado da consulta colaborativa é fornecer programas abrangentes e eficazes para alunos com necessidades especiais dentro do contexto mais apropriado, permitindo-lhes alcançar a máxima interação construtiva com seus pares sem deficiência (IDOL; PAOLUCCI-WHITCOMB; NEVIN, 1986, p. 1).

Nas definições e caracterizações apresentadas, as noções de mutualidade e reciprocidade fazem parte de uma suposta ideia de uma natureza colaborativa. De um lado, a mutualidade consiste em compartilhar a propriedade de uma questão ou de um problema comum entre os profissionais. De outro, a reciprocidade está em permitir que essas partes tenham igual acesso à informação e à oportunidade de participar na identificação de problemas, discussão, tomada de decisões e de resultados (WEST, 1988).

Sob essas condições, West e ldol (1990) apontam que o professor de sala regular e o da educação especial são responsáveis por trabalhar em conjunto para definir o problema, elaborar um plano apropriado, cumprir suas responsabilidades relevantes e avaliar o impacto do que eles fizeram. Ambos estabelecem juntos o problema e criam as soluções criativas para resolvê-lo, de forma que sejam solidariamente responsáveis pelo resultado obtido de um aluno em particular.

Nessa perspectiva, os autores afirmam que essa relação colaborativa cria "empoderamento mútuo" (WEST; IDOL, 1990), pois, em vez de o professor especialista ser uma ameaça para o desenvolvimento do trabalho do professor de sala regular, esse processo permite que os profissionais enfrentem os problemas juntos e agrupem suas várias fontes de conhecimento para resolver da melhor forma a questão apresentada. Desse modo, o empoderamento mútuo torna-se um dos principais objetivos da colaboração educacional.

Depois da caracterização da consulta escolar colaborativa, no seguinte tópico, apresentaremos, em termos iniciais, as particularidades do modelo de colaboração chamado de coensino ou ensino colaborativo.

\section{Coensino ou ensino colaborativo}

As raízes do coensino (co-teaching, em inglês), como uma opção de prestação de serviços da educação especial, são encontradas na configuração 
do ensino em equipe entre professores da educação regular. Apesar de suas múltiplas variações, o coensino visava a criar ambientes educacionais centrados no aluno (FRIEND; REISING; COOK, 1993).

Dessa forma, o coensino surge como uma variação do ensino em equipe e é definido como a relação entre dois ou mais profissionais, proporcionando um ensino relevante a um grupo diversificado de alunos num único espaço físico (COOK; FRIEND, 1995). Esse significado baseia-se no conceito de colaboração entendido como "[...] um estilo de interação entre pelo menos duas partes coiguais empenhadas, voluntariamente, na tomada de decisões compartilhadas enquanto trabalham em direção a uma meta comum" (FRIEND; COOK, 1990, p. 2, tradução nossa).

A partir dos anos de 1980, o coensino passa a ser amplamente utilizado na área de educação especial, como uma atividade realizada entre o professor de sala regular e o da educação especial, os quais estão envolvidos ativamente no ensino de um grupo diverso de estudantes, incluindo alunos com deficiência. $\bigcirc$ ensino é oferecido, principalmente, numa única sala de aula ou espaço físico (COOK; FRIEND, 1995).

Nesse sentido, tendo como princípio a relação colaborativa, o coensino pode acontecer em diversas formas e adquirir diferentes denominações. No caso de Cook e Friend (1995), o coensino abrange a colaboração em todas as facetas do processo educacional, desde a avaliação de forma colaborativa das forças e fraquezas dos estudantes, para a determinação de objetivos educacionais e indicadores de resultados apropriados por meio do planejamento de estratégias de intervenção, até a implementação e avaliação do progresso do aluno em direção às metas estabelecidas e à eficácia do processo de coensino.

Fundamentando-se nessa ideia, os autores desenvolveram os seguintes níveis de coensino: a) ensino assistido: baseado numa ordem hierárquica, na qual um professor está no comando da sala de aula e o outro observa os estudante ou ajuda-os nas atividades propostas; b) estação de ensino: os professores dividem o conteúdo da aula em duas ou mais partes para ser ensinado em pequenos grupos de alunos; c) ensino paralelo: os professores realizam o plano de ensino em conjunto, porém cada um será responsável por ensinar a metade do conteúdo; d) ensino alternativo: permite aos professores proporcionar diversas abordagens para um grupo pequeno de estudantes; e) ensino em equipe: forma mais desenvolvida do coensino, na qual os dois professores 
compartilham o ensino dos alunos. É o tipo de ensino que requer o nível mais alto de confiança e compromisso.

Por sua vez, as opções identificadas por Bauwens, Hourcade e Friend (1989) sobre o ensino colaborativo (collaborative teaching, em inglês) evidenciam a necessidade do professor do ensino regular e o da educação especial compartilhar a mesma sala de aula. Os autores descreveram as seguintes opções: a) ensino complementar; b) ensino em equipe; e c) atividades de apoio para a aprendizagem.

O ensino complementar permite ao professor do ensino regular manter a responsabilidade principal pelo conteúdo de ensino, enquanto o professor de educação especial ensina estratégias e habilidades para dominar o assunto (BAUWENS; HOURCADE; FRIEND, 1989).

$\bigcirc$ ensino em equipe é definido como um subtipo do coensino, no qual os professores da educação especial e os do ensino regular planejam em conjunto e ensinam o conteúdo, porém assumem diversos níveis de responsabilidade para diferentes segmentos do currículo ou tipos de ensino (BAUWENS; HOURCADE; FRIEND, 1989).

As atividades de apoio para a aprendizagem configuram-se de 16 maneira que o professor do ensino regular seja responsável por ensinar o conteúdo curricular, enquanto o professor de educação especial fica encarregado de providenciar atividades de reforço e suplementares para a aprendizagem do aluno (BAUWENS; HOURCADE; FRIEND, 1989).

Da mesma forma, Pugach e Johnson (1995) utilizam o termo ensino em equipe para descrever seu modelo de coensino e estabelecem orientações específicas para os indivíduos que optam por envolver-se nessa atividade colaborativa. Para tanto, os autores ressaltam que, antes de formar as equipes, os participantes devem concordar que o objetivo inicial é "[...] um esforço conjunto para melhorar o processo de ensino-aprendizagem, implementando as abordagens contemporâneas disponíveis mais eficazes ao currículo e ao ensino" (PUGACH; JOHNSON, 1995, p. 177, tradução nossa).

Nessa perspectiva, os autores estabelecem os seguintes princípios orientadores: a) desafiar-se a si mesmo para melhorar o próprio ensino;

b) compartilhar a responsabilidade do ensino e de todos os alunos; c) ter comunicação regular; d) apoiar os membros da equipe; e el trabalhar ativamente para incluir todos os alunos (PUGACH; JOHNSON, 1995). Cabe ressaltar que, na discussão desses princípios, os autores não se referem 
diretamente à presença física de ambos os professores na sala de aula. Contudo, a maior parte da discussão é permeada pela ética colaborativa e implica que ambos estejam presentes (REINBILLER, 1996).

Para finalizar esta descrição e análise iniciais sobre o conceito de colaboração, percebemos que os diversos modelos de colaboração entre os professores regentes e os da educação especial se configuraram, inicialmente, por uma questão econômica, já que era necessária uma mudança organizacional na educação especial para reduzir as despesas nessa área e tornar os alunos com algum tipo de deficiência ou problemas de aprendizagem sujeitos mais produtivos.

Dessa maneira, inferimos uma forma de inclusão dos alunos com deficiência ou problemas de aprendizagem nas escolas regulares norte-americanas por meio dos modelos de colaboração, com a finalidade de atingir o viés capitalista. Ao mesmo tempo, essa ideia vai sendo mais esclarecida, ao percebermos que esses modelos parecem estar alinhados ao conceito de colaboração utilizado pelas organizações/empresas, pois trazem consigo o pressuposto de estabelecer uma relação eficaz, baseada no empenho voluntário, compartilhamento e empoderamento mútuo para resolver os problemas da melhor forma e atingir a eficácia do processo de ensino.

\section{Considerações finais}

De modo geral, observamos que a colaboração se conceitua dentro do sistema relacional de trabalho em conjunto, como uma ferramenta psicológica aplicada aos trabalhadores para gerar mudanças organizacionais e atingir objetivos relacionados com a produção eficaz da organização/ empresa. Assim, sob a base de um sistema relacional de trabalho em conjunto com os discursos de cuidado humano, compromisso e justiça, a colaboração é estabelecida como parte da reconfiguração do sistema capitalista que continua explorando o trabalhador por meio de novos mecanismos que melhorem sua produtividade e proporcionem maiores lucros econômicos.

Parece, então, que a conceituação da colaboração tem se deslocado do ambiente empresarial para o ambiente escolar em múltiplas formas e modalidades, atingindo também a educação especial. Isso se justifica na ideia de que a escola, ao ser parte de uma totalidade histórica composta 
por condicionamentos políticos, econômicos e sociais, é também perpassada pelas mudanças organizacionais exigidas pelo capital.

Nesse sentido, cabe estudar com maior profundidade o conceito de colaboração entre os professores regentes e os da educação especial em suas diversas formas e modalidades desenvolvidas no Brasil, já que é importante contribuir com práticas educativas que objetivem desenvolver a humanidade produzida histórica e coletivamente pelos homens nos alunos público-alvo da educação especial e lutar contra práticas que perpetuem a lógica do capital.

\section{Nota}

1 Devido à multiplicidade de sentidos atribuídos ao conceito de colaboração em diversas pesquisas na área de educação especial, referimo-nos à colaboração entre os professores regentes e os da educação especial como uma "prática colaborativa" (BRASIL, 2008). Já quando citamos outros trabalhos, deixamos de forma textual as palavras utilizadas pelos autores para se reportarem a essa colaboração.

2 Com a PNEEPEI (BRASIL, 2008), a terminologia "educandos com necessidades educacionais especiais" é substituída por "público-alvo da educação especial", comportando os alunos com deficiência, transtornos globais do desenvolvimento e altas habilidades/superdotação, a fim de delimitar os sujeitos encaminhados ao atendimento educacional especializado.

$3 \bigcirc$ comprometimento é definido como a consciência do direito mútuo e a responsabilidade ao longo do tempo (APPLEY; WINDER, 1977).

4 Independentemente de que, nas produções científicas no Brasil, seja mais usada a expressão "ensino colaborativo" para se referir à parceria entre os professores de sala de aula e os da educação especial no ensino regular, nesta parte do trabalho, optaremos por utilizar a tradução literal dos termos "co-teaching" e "collaborative teaching" conforme o uso dos autores citados.

\section{Referências}

GARCIA, Alejandro Sanchez. History and fundaments of organizational development. Jornal of Global Economics, v. 4, n. 4, p. 1-5, nov. 2016.

APPLEY, Dee G.; WINDER, Alvin E. An evolving definition of collaboration and some implications for the world of work. The Journal of Applied Behavioral Science, v. 13, n. 3, p. 279-291, 1977. 
BAUWENS, Jeanne; HOURCADE, Jack Joseph; FRIEND, Marilyn. Cooperative teaching: a model for general and special Education. Remedial And Special Education, v. 10, n. 2, p. 17-22, 1989.

BOSZORMENYI-NAGY, Ivan; SPARK, Geraldine M. Invisible loyalties, reciprocity in intergenerational family therapy. New York: Harper \& Row, 1973.

BRASIL. Política Nacional de Educação Especial na Perspectiva da Educação Inclusiva. Disponível em: http://portal.mec.gov.br/arquivos/pdf/politicaeduc especial.pdf. Acesso em: 20 set. 2019.

BRASIL. Resolução CNE/CEB n² 2, de 11 de setembro de 2001. Estabelece as Diretrizes Nacionais para a Educação Especial na Educação Básica. Disponível em: http://portal. mec.gov.br/cne/arquivos/pdf/CEBO201.pdf. Acesso em: 10 mar. 2018.

BRASIL. Resolução CNE/CEB $\mathbf{n}^{\circ}$ 4, de 2 de outubro de 2009. Estabelece as Diretrizes Operacionais para o Atendimento Educacional Especializado na Educação Básica, modalidade Educação Especial. Disponível em: http://portal.mec.gov.br/dmdocuments/ rceb004_09.pdf. Acesso em: 10 de mar. 2018.

BROWN, Duane; WYNE, Marvin D.; Blackburn, Jack E.; Powell, W. Conrad. Consultation: strategy for improving education. Boston: Allynand Bacon, 1979.

BURNS, Tom; STALKER, George. The management of innovation. London: Tavistock Publications, 1961.

CAPELLINI, Vera Lúcia. Avaliação das possibilidades do ensino colaborativo no processo de inclusão escolar do aluno com deficiência mental. 2004. 302 f. (Tese de Doutorado) Programa de Pós-Graduação em Educação Especial, Universidade Federal de São Carlos, 2004.

COOK, Lynne; FRIEND, Marilyn. Co-teaching: guidelines for creating effective practices. Focus on Exceptional Children, v. 28, n. 3, p. 1-16, 1995.

CURY, Carlos Roberto Jamil. Educação inclusiva como Direito. In: VICTOR, Sonia Lopes; OlIVEIRA, Ivone Martins de (Org.). Educação especial: políticas e formação de professores. Marília: ABPEE, 2016.

DAMANPOUR, Fariborz; GOPALAKRISHNAN, Shanthi. Theories of organizational structure and innovation adoption: the role of environmental change. Journal of Engineering and Technology Management, n. 15, p. 1-24. 1998. 
FRIEND, Marilyn; COOK, Lynne. Collaboration as a predictor for sucess in school reform. Journal of Educational and Psychological Consultation, v. 1, n. 1, p. 69-86, 1990.

FRIEND, Marilyn; REISING, Monica; COOK, Lynne. Co-Teaching: an overview of the past, a glimpse at the present, and considerations for the future. Preventing School Failure: alternative Education for Children and Youth, v. 37, n. 4, p. 6-10, jul. 1993.

FRIGOTTO, Gaudêncio. $\bigcirc$ enfoque da dialética materialista histórica na pesquisa educacional. In: FAZENDA, Ivani Catarina Arantes Fazenda (Org.). Metodologia da pesquisa educacional. 2. ed. São Paulo: Cortez, 1991.

GHORBANHOSSEINI, Masoud. The effect of organizational culture, team work and organizational development on organizational commitment: the mediating role of human capital. Tehniki Vjesnik, v. 20, n. 6, p.1019-1025, 2013.

HERON, Timothy; HARRIS, Kathleen. The educational consultant. Boston: Allyn and Bacon, 1982.

IDOL, Lorna; PAOLUCCI-WHITCOMB, Phyllis; NEVIN, Ann. Collaborative consultation. Rockville: Aspen, 1986.

20 IDOL-MAESTAS, Lorna. A teacher training model:
Disorders, v. 6, n. 2, p. 108-121, fev. 1981.

KINGDON, Donald Ralph. Matrix organization: managing information technologies. London: Tavistock Publications, 1973.

LITTLE, Judith Warren. The power of organizational setting: norms and staff development. In: ANNUAL MEETING OF THE AMERICAN EDUCATIONAL RESEARCH ASSOCIATION, 1981, Los Angeles. Anais [...]. Los Angeles: National Institute Of Education, 1981.

MENDES, Enicéia Gonçalves; VILARONGA, Carla Ariela Rios; ZERBATO, Ana Paula. Ensino colaborativo como apoio à inclusão escolar: unindo esforços entre educação comum e especial. São Carlos: EdUFSCar, 2014.

MEYERS, Joel; PARSONS, Richard D.; MARTIN, Roy. Mental health consultation in the schools. San Francisco: Jossey-Bass, 1979.

MYERS, Mary Elizabeth. A study of team teaching as implemented in the elementary school. 1968. 176 f. Monografia (Especialização em Educação) - Programa de PósGraduação em Educação, Illinois Wesleyan University, Bloomington, 1968. 
PRIETO, Rosangela Gravioli. Política de educação especial no Brasil: evolução das garantias legais. In: SEMINÁRIO CAPIXABA DE EDUCAÇÃO INCLUSIVA, 11 ., 2008, Vitória. Anais [...]. Vitória: Universidade Federal do Espirito Santo, 2008.

PRIETO, Rosangela Gravioli; COSMO, Norma Celiani; ANACHE, Alexandra Ayach. 10 anos da política nacional de educação especial na perspectiva da educação inclusiva. In: CONGRESSO BRASILEIRO PSICOLOGIA: CIÊNCIA E PROFISSÃO, 5., 2018, São Paulo, Mesa_Redonda [...]. São Paulo: Ufscar, 2018. Disponível em: https://www.youtube.com/ watch? $v=$ rgUONOG9_Zk\&t=1435s. Acesso em: 26 ago. 2019.

PUGACH, Marleen Carol; JOHNSON, Lawrence J. Collaborative practitioners, collaborative schools. Denver: Love Publishing, 1995.

REINBILLER, Noell. Coteaching: new variations on a not-no-new practice. Teacher Education and Special Education: the Journal of the Teacher Education Division of the Council for Exceptional Children, v. 19, n. 1, p. 34-48, jan. 1996.

SHAPLIN, Judson T.; OLDS, Henry F. Junior. Team teaching. New York: Harper \& Row Publishing Co., 1964.

TRIST, Eric. Collaboration in worksettings: a personal perspective. The Journal of Applied Behavioral Science, v. 13, n. 3, p. 268-278. 1977.

TRUMP, J. Lloyd; BAYNHAM, Dorsey. Guide to better schools: focus on change. Chicago: RandMcnally, 1961.

WEST, John Frederick. The future of school consultation: forces, issues, and strategies. In: WEST, John Frederick (Ed.). School consultation: interdisciplinary perspectives on theory, research, training and practice. Austin: Association For Educational And Psychological Consultants, 1988.

WEST, John Frederick; IDOL, Lorna. Collaborative consultation in the education of mildly handicapped and at-risk students. Remedial and Special Education, v. 1 1, n. 1, p. 22-31, jan. 1990.

WEST, John Frederick; IDOL, Lorna. School Consultation (Part I): an interdisciplinary perspective on theory, models, and research. Journal of Learning Disabilities, v. 20, n. 7, p. 388-408, ago. 1987.

ZANATA, Eliana Marques. Práticas pedagógicas inclusivas para alunos surdos numa perspectiva colaborativa. 2004. 201 f. (Tese de Doutorado) - Programa de Pós-Graduação em Educação Especial, Universidade Federal de São Carlos, São Carlos, 2004. 
Mestranda Alejandra Cesarina Rodriguez Paz

Universidade Federal do Espírito Santo (Brasil)

Programa de Pós-Graduação em Educação

Grupo de Pesquisa Infância, Cultura, Inclusão e Subjetividade (Grupicis) ORCID: https:/ / orcid.org/0000-0002-235 1-4798

E-mail: alerodpaz@gmail.com

Prof. ${ }^{a}$ Dr. ${ }^{a}$ Sonia Lopes Victor

Universidade Federal do Espírito Santo (Brasil)

Centro de Educação

Programa de Pós-Graduação em Educação

Departamento de Teorias de Ensino e Práticas educacionais

Grupo de Pesquisa Infância, Cultura, Inclusão e Subjetividade (Grupicis)

ORCID:https://orcid.org/0000-0002-9492-6933

E-mail: sonia.victor@hotmail.com

Recebido 3 out. 2019

Aceito 13 dez. 2019 